\title{
SENTENCIA SOBRE REQUISITOS DE PROCEDENCIA Y FINALIDAD DE LA COMPENSACIÓN ECONÓMICA (CORTE DE APELACIONES DE VALDIVIA)
}

\author{
Comentario de Susan Turner Saelzer
}

Valdivia, tres de mayo de dos mil seis.

VISTOS y OIDOS:

PRIMERO: Que con fecha 26 de abril del presente, se llevó a efecto la audiencia de juicio correspondiente a los autos RUC 05-2-0043186-5 RIT C-3672005, para conocer de $1 \mathrm{ft}$ demanda formulada por doña Eduvigis del Carmen Vejar.

García C.I 5.586.330-K, 55 años de edad, casada, secretaria, domiciliada en calle General Lagos pasaje Di Biaggio N 121 de esta ciudad, la demandante interpuso demanda de divorcio y de compensación económica en contra de don Roberto Osvaldo Soto Oyarzo, C.I. N N $^{0}$ 7.492.619-3, 51 años de edad, casado, empresario, domiciliado en Avenida Pedro Montt, pasaje Álvaro Bombal Nº 030, Valdivia.

La parte demandante compareció representada por el abogado Sr. Carlos Alejandro Hidalgo Muñoz.

El demandado fue debidamente emplazado, y no compareció a la audiencia preparatoria ni a la audiencia de juicio.

SEGUNDO: Que doña Eduvigis del Carmen Véjar García, funda su demanda de divorcio, en que contrajo matrimonio con el demandado el 23 de diciembre de 1972, en la comuna de Lago Ranco, del matrimonio nacieron dos hijas, en la actualidad mayores de edad. Durante el año 1972-1973 era funcionaria de Endesa, y en consideración a que el demandado no encontró trabajo y tenía la posibilidad de seguir estudiando, decidió apoyarlo para que entrara a estudiar a la Universidad Austral la barrera de Ingeniería en electricidad, más tarde, quedó sin trabajo, había nacido su primera hija Evelyn, y comenzó a trabajar como secretaria de gerencia en el Astillero Immar y a mediados del año 1976 ingresó a trabajar a la Universidad Austral, donde lleva más de 28 años trabajando. Su cónyuge abandonó los estudios, época en la que ella debió solventar los gastos familiares, incluida la manutención del demandado, nunca dejó de trabajar y pudo asistir a sus dos hijas, además de contribuir económicamente al hogar, costumbre que para el demandado fue muy cómoda, lo que le permitió ahorrar e ir adquiriendo bienes. El 28 de agosto de 1999, mientras ella se encontraba trabajando, el demandado abandonó el hogar común, con lo cual cesó la convivencia, procediendo a retirar del 
hogar todos los objetos que quiso, como televisor, equipo, computador, además tenía una camioneta, la cual vendió. Agrega, que el demandado siempre fue una persona muy violenta, lo que a ella le significó una enorme crisis emocional y un desgaste psíquico de abatimiento y fracaso, realizó diversas denuncias ante Carabineros por malos tratos físicos y psíquicos, incluso hay causas por violencia intrafamiliar. En la causa rol 293-2002 por violencia intrafamiliar, fueron fijados los alimentos, alimentos que el demandado cumplió durante cierto tiempo, pero que a la fecha ha dejado de pagar, y no han sido regulados en la instancia correspondiente. Por lo que solicita en virtud del artículo 55 de la Ley de Matrimonio Civil, tener por deducida demanda de divorcio, declarar terminado el matrimonio, ordenando las inscripciones y subinscripciones que corresponda.

Se tuvo por evacuada la contestación de la demanda en rebeldía del demandado.

TERCERO: Que: doña Eduvigis del Carmen Véjar García interpuso demanda de compensación económica en contra de don Roberto Osvaldo Soto Oyarzo, señalando que durante años ha asumido en gran parte la manutención y cuidado de sus hijas y del demandado, generándose por este hecho una evidente situación de menoscabo económico. Durante años el demandado estudiaba mientras ella trabajaba y cuidaba del hogar común, nunca dejó de trabajar y asistir económicamente a sus hijas contribuyendo sola a los gastos del hogar, costumbre que para el demandado fue muy cómoda, lo que le permitió ahorrar e ir adquiriendo sus propios bienes. Tuvo fondos mutuos por sumas superiores a $\$ 2.000 .000$, que posteriormente ocupó para remodelar la casa que recibió como herencia de sus padres, casa que actualmente ocupa en parte para vivir con su actual pareja, y la otra mitad la tiene dada en arrendamiento. Fue el demandado quien abandonó el hogar común. Durante el tiempo que él estudió ella debió endeudarse solicitando créditos en la Universidad, y que el demandado a pesar de haber estudiado en forma diurna y haberse dedicado en forma íntegra a sus estudios, no se tituló como ingeniero. Por lo que solicita a título de compensación económica la suma de $\$ 10.000 .000$ o lo que en justicia y derecho se determine por el tribunal.

Se tuvo por evacuada la contestación de la demanda en rebeldía del demandado.

CUARTO: Que en la audiencia preparatoria celebrada el 14 de marzo de 2006, se hizo el llamado especial de conciliación de acuerdo a lo dispuesto en la Ley de Matrimonio Civil en rebeldía del demandado, aplicando supletoriamente las normas del Código de Procedimiento Civil, y se dio curso al procedimiento, dictando la resolución que cita a audiencia de juicio.

QUINTO: Que el objeto del juicio es determinar la procedencia del divorcio unilateral y la procedencia y monto de la compensación económica demandada.

SEXTO: Que no se acordaron convenciones probatorias entre las partes. 
SÉPTIMO: Que en la audiencia de juicio se rindió en forma legal, la siguiente prueba por la parte demandante del divorcio:

\section{Prueba documental:}

a) Certificado de matrimonio de las partes del juicio, que acreditan que contrajeron matrimonio el 23 de diciembre de 1972, inscripción $\mathrm{N}^{\circ} 53$, año 1972, circunscripción de Lago Ranco.

b) Certificados de nacimiento de las hijas en común Loreto Estefanía y Evelyne Andrea Soto Véjar, nacidas el 21 de diciembre de 1984 y el 12 de diciembre de 1973 , de 21 y 32 años de edad, respectivamente.

\section{Prueba testimonial:}

1. María Violeta Sepúlveda Coronado, quien expuso que conoce a la demandante hace cuatro años, y desde que la conoce ella vive sola con sus dos hijas. Ella le contó que se habían separado en 1999, y que el quiebre se produjo por maltrato físico, y además él se fue porque tiene otra pareja.

2. Silvia Rosa Silva Guerrero, quien señala que conoce a la demandante hace más de diez años porque son colegas de trabajo en la Universidad, por lo que sabe que ella se encuentra separada de hecho del demandado desde el año 1999, él se fue de la casa, hubo una tercera persona. Agrega, que desde que se separaron nunca más volvieron a vivir juntos.

OCTAVO: Que en la referida audiencia la demandante de compensación económica rindió prueba testimonial consistente en la declaración de:

1. Haydée Victoria Alvarado Cid quien expuso que conoce hace quince años a la demandante por funciones laborales, la conoció en un curso de costura que la demandante dictaba en la Universidad, no conoce al demandado, pero sabe que están separados. La demandante le dio educación a sus hijas y al esposo, ella era la que se esforzaba más por sacarlo adelante, él invertía o malgastaba el dinero con otras personas. El demandado se fue de la casa, y se llevó televisor, vehículo, equipo. Hay un daño moral y un desgaste físico y emocional para la actora, ella no pudo seguir perfeccionándose, no tuvo tiempo ni plata para hacerlo.

2. María Cecilia Pizarro Ponce, quien señaló que conoce a la demandante desde el año 1998, primero la conoció porque era asesora provisional y luego porque pertenecían al mismo grupo cristiano, por lo que sabe que está separada desde el año 1999, se separó por infidelidades y malos tratos de parte de su cónyuge, le pagó los estudios a su esposo y a sus hijas, ha debido pedir préstamo sobre préstamo.

Además se incorporó como prueba documental, certificado de alumno regular de fecha 13 de septiembre de 2005, emitido por la Universidad Austral de Chile el que 
indica que el demandado ingresó en el año 1973 a la carrera de Ingeniería de Ejecución en Electrónica y registra última matrícula en el año 1983, se informa en el documento que registró matrículas desde el año 1973 a 1983, en forma ininterrumpida, y que el régimen de estudios fue semestral, diurno; certificado de alumno regular de fecha 22 de agosto de 2005, emitido por la Universidad Austral de Chile en el cual se señala que Loreto Estefanía Soto Véjar es alumna regular de la carrera de Fonoaudiología, carrera a la que ingresó en el año 2004; constancia emitida por el Director de Asistencia Técnica y Capacitación de la Facultad de Ciencias Económicas y Administrativas de la Universidad Austral de Chile en que se indica que el demandado cursó y aprobó el diplomado en Gestión de Empresas dictado durante el año académico 1993; copia simple de la inscripción de dominio de fecha 25 de abril de 2000, en la cual se señala que el demandado compra acciones y derechos sobre la propiedad ubicada en el lugar denominado El Pantano, hoy pasaje Álvaro Bombal número treinta; informe de crédito de la Caja de Compensación Los Andes a nombre de la demandante; copias de solicitud de aporte a Fondo Mutuo por diferentes sumas efectuadas por el demandado en diferentes fechas del año 1996, 1997 y 1998; certificado del Fondo de Ahorro y Asistencia del Personal Académico de la Universidad Austral de Chile, en que se hace referencia a los préstamos solicitados por la actora a dicha repartición durante los años 1996, 2000, 2001 y 2002; certificados de inscripción y anotaciones vigentes en el Registro de Vehículos Motorizados de un camión y una camioneta inscritas a nombre del Sr. Soto Oyarzo y fotografía de una embarcación pequeña con motor.

NOVENO: Que se incorporó en la audiencia la prueba decretada por el tribunal, consistente en causas rol 293-2002 del Primer Juzgado Civil de esta ciudad por violencia intrafamiliar, en dicho proceso y con fecha 20 de diciembre de 2001 el demandado fue condenado como autor de hechos constitutivos de violencia intrafamiliar y fotocopias de la causa1632-2002 del Segundo Juzgado del Crimen de Valdivia, por manejo en estado de ebriedad, seguida en contra del demandado, en la cual figura como su domicilio Álvaro Bombal No 30 de esta ciudad. Además, declaraciones formularios 22 correspondientes a la renta declarada por don Roberto Osvaldo Soto Oyarzo durante los años 2000 al 2005 y formularios 29 de IVA.

DÉCIMO: Que, apreciada la prueba rendida de acuerdo a las reglas de la sana crítica, el hecho del cese de la convivencia con anterioridad al plazo requerido por la Ley, y que en el tiempo intermedio no ha operado reconciliación, se tendrá por suficientemente acreditado con el mérito de la prueba testimonial rendida, y documental incorporada en la audiencia de juicio que acreditan que los cónyuges se encuentran separados de hecho desde el año 1999.

DÉCIMO PRIMERO: Que en lo que se refiere a la demanda por compensación económica, y ponderando de conformidad a la ley los elementos de prueba rendidos durante la audiencia de juicio, es decir, de acuerdo con las reglas de la sana crítica, sin contradecir los principios de la lógica, las máximas de la experiencia, ni los conocimientos científica- 
mente afianzados, el tribunal estima acreditado que la demandante ha trabajado siempre, desde que contrajo matrimonio a la fecha, desempeñando principalmente funciones como secretaria; que mientras su cónyuge estudiaba en la Universidad Austral desde el año 1973 hasta el año 1983 era ella quien sustentaba el hogar, realizando todos los esfuerzos necesarios para la mantención de su familia incluyendo el cuidado de sus hijas.

Si nos remitimos al texto de la ley, al artículo 61 de la ley 19.947, y habiéndose acreditado que la demandante desarrolló una actividad lucrativa o remunerada durante el matrimonio, el menoscabo económico requisito indispensable para que proceda la compensación demandada debe ser causado por el hecho de haber desarrollado esta actividad remunerada o lucrativa en menor medida de lo que podía y quería, y a este respecto, no existen antecedentes probatorios en esta causa que demuestren de qué manera la actora por cuidar a los hijos o dedicarse a las labores propias del hogar desarrolló una actividad remunerada durante la vida matrimonial en menor medida de lo que podía y quería; está claro que trabajó, y que lo hizo incluso en exceso, para sustentar a su familia formada por su cónyuge e hijas, que contrajo deudas, que su cónyuge pudo estudiar en la Universidad y posteriormente generar ingresos que le permitieron ahorrar sumas de dinero, y está claro, también, que los hechos detallados formaron parte del proyecto de vida de los cónyuges, proyecto que se vio frustrado por la separación de la pareja.

Que en atención a lo expuesto no ha logrado demostrarse la efectividad del menoscabo económico, y al no haberse acreditado las condiciones necesarias para que proceda la compensación demandada, forzoso será rechazarla.

DÉCIMO SEGUNDO: Que al ponderar los medios de prueba señalados precedentemente en esta sentencia, el tribunal ha tenido en consideración que los dichos de los testigos que han declarado en estrados, coinciden y resultan coherentes con la demás prueba documental incorporada en la audiencia de juicio.

DÉCIMO TERCERO: Que, por lo señalado, se acogerá la demanda de divorcio unilateral deducida, rechazándose la demanda de compensación económica y así se indicará en lo resolutivo de este fallo.

Y, vistos, además lo dispuesto en los artículos 53, 55, 59, 60, 61, 64, 67, 68, 85 y siguientes de la Ley 19.947; y artículos $8 \mathrm{~N}^{\circ} 16$ y 55 y siguientes de la ley 19.968, SE DECLARA:

1. Que se acoge, con costas, la demanda de divorcio deducida por doña EDUVIGIS DEL CARMEN VÉJAR GARCÍA en contra de don ROBERTO OSVALDO SOTO OYARZO, declarándose en consecuencia, terminado el vínculo matrimonial entre ellos, celebrado el 23 de diciembre de 1972, inscrito con el $\mathrm{N}^{\circ} 53$ del Registro de Matrimonios de la circunscripción de Lago Ranco, del Registro Civil correspondiente al año 1972.

2. Que se rechaza la demanda de compensación económica interpuesta por doña Eduvigis del Carmen Véjar García en contra de don Roberto Osvaldo Soto Oyarzo, sin costas, por haber tenido motivos plausibles para litigar. 
Ejecutoriada que sea esta sentencia, subinscríbase el divorcio al margen de la respectiva inscripción de matrimonio.

Regístrese y archívese oportunamente.

Consúltese, si no se apelare.

RIT C-367 -2005

\section{Dictada por doña Monica Sanhueza Kusch, Juez de Familia}

VALDIVIA, siete de julio de dos mil seis.

\section{VISTOS:}

Se reproduce la sentencia en alzada, con excepción de sus razonamientos a décimo tercero, que se eliminan.

\section{Y TENIENDO ADEMÁS, Y EN SU LUGAR PRESENTE:}

PRIMERO.- Que los certificados de depósitos en fondos mutuos efectuados por el demandado, acompañado a los autos, son del siguiente monto y fecha: 8 de octubre de 1998: \$300.000; 4 de septiembre de 1998: \$250.000; 23 de julio de 1998: \$300.000; 26 de junio de 1998: \$430.000; 14 de mayo de 1998: \$150.000; 20 de diciembre de 1996: \$300.000; 10 de octubre de 1997: $\$ 2.200 .000 ; 10$ de diciembre de 1997: \$7.127.722; 18 de diciembre de 1996: \$7.282.080; 7 de octubre de 1996: $\$ 700.000$; 7 de noviembre de 1996: \$ 1.200.000; 24 de octubre de 1996: \$ 400.000; 2 de noviembre de 1996: \$400.000 y 21 de noviembre de 1996: \$ 600.000 todos ellos efectuados mientras se mantenía la convivencia entre las partes.

SEGUNDO.- Que apreciada la prueba rendida de acuerdo a las reglas de la sana crítica, sin contradecir los principios de la lógica y las máximas de experiencia, ni los conocimientos científicamente afianzados, es dable concluir que la actora quien demanda compensación económica, trabajó durante toda la vigencia del matrimonio, en un cargo de Secretaria en la Universidad, sin título universitario, dedicándose además a mantener y educar al demandado, quien obtuvo un título universitario, y un grado académico de post grado, sin que se acreditara que en tales periodos desempeñó una labor remunerada, de manera que inequívocamente lo fue financiada por su cónyuge.

De otro lado, si mientras se mantuvo la convivencia, el demandado estuvo en condiciones de efectuar depósitos en fondos mutuos por cantidades superiores a $\$ 10.000 .000$ en 1996 , de \$2.500.000 en 1997 y \$1.280.000 en el año 1998, fue porque lo obtuvo con la ayuda y gracias al esfuerzo de trabajo de la actora.

TERCERO.- Que si bien la actora mientras se mantuvo la convivencia trabajó y obtuvo una remuneración, que duda cabe lo hizo en un cargo no profesional, sin que ninguna 
alternativa tuviera de perfeccionarse en sus estudios, pues dabía mantener el hogar común y pagar estudios, no sólo de sus hijas sino también del cónyuge demandado.

CUARTO.- Que los razonamientos precedentes hacen concluir a estos sentenciadores, que es plenamente procedente la compensación económica solicitada por la demandante, pues inequívocamente sufrió menoscabo económico durante la convivencia, desde que es al demandado a quien se le ha acreditado nivel de vida e ingresos cuantiosos y no a la demandada.

Por estas consideraciones y visto además lo dispuesto por los artículos 223 y 227 del Código de Procedimiento Civil y de los Tribunales de Familia y se declara:

Que se REVOCA la sentencia apelada de tres de mayo de dos mil seis escrita a fojas 132 a 137, en cuanto no hace lugar a la demanda de compensación económica solicitada por la actora y se declara en cambio: Que se ACOGE dicha demanda, con costas, fijándose dicha compensación en la suma de \$10.000.000.

Acordada con el voto en contra de Ministro don Juan Ignacio Correa Rosado, quien estuvo por confirmar la sentencia apelada, en virtud de sus propios fundamentos.

Regístrese y devuélvase.

Rol No 196-2006.-

Redacción de la Ministra señora Emma Díaz Yévenes.

No firma el Ministro señor Juan Ignacio Correa Rosado no obstante haber concurrido a la vista y acuerdo del fallo por encontrarse con permiso.

\section{COMENTARio}

En el fallo transcrito, la Corte de Apelaciones de Valdivia revocó la sentencia de divorcio dictada en primera instancia en lo concerniente a la compensación económica solicitada por la demandante, dando lugar a ella y fijándola en la suma de $\$ 10.000 .000$.

El caso fallado presenta algunas particularidades que ameritan una reflexión acerca de dos aspectos esenciales de la compensación económica: sus requisitos de procedencia y la finalidad que, de acuerdo con su naturaleza jurídica, está llamada a cumplir en el ordenamiento matrimonial chileno.

En cuanto a los requisitos de procedencia de la prestación compensatoria, es interesante que en este caso fue la mujer -demandante de la compensación económica- la que trabajó remuneradamente mientras duró la convivencia conyugal proveyendo a las necesidades de la familia. En efecto, la propia demandante sostiene como fundamento de su pretensión compensatoria el haber trabajado fuera del hogar en forma lucrativa durante todo el matrimonio, además de haber cuidado del hogar común, contribuyendo sola a los gastos del mismo. Este hecho constituiría el origen de la "evidente situación de menoscabo económico” en que se encontraría la demandante (considerando $3^{\circ}$ ). Por su parte, toda la actividad probatoria relacionada con la compensación económica estuvo encaminada a acreditar que fue la mujer la que trabajó remuneradamente durante el matrimonio, cuestión que el tribunal a quo finalmente dio por probada según las reglas 
de la sana crítica $\left(\right.$ considerando $11^{\circ}$ ). Consecuentemente con lo anterior y en forma acertada, a mi juicio, dicho tribunal rechazó la procedencia de la compensación económica solicitada por la mujer por faltar el menoscabo económico exigido por el art. 61 LMC.

Por el contrario, el tribunal de alzada concluyó que la demandante sufrió "inequívocamente" un menoscabo económico durante la convivencia, "desde que es al demandado a quien se le ha acreditado nivel de vida e ingresos cuantiosos y no a la demandada" (considerando $4^{\circ}$ ). Esta conclusión pudiera parecer, desde un punto de vista de justicia material, más acertada que la de la jueza de primera instancia en atención a que los hechos dan cuenta de una mujer que destinó toda su fuerza de trabajo y capacidad intelectual al mantenimiento de sus hijas y de su marido, sin colaboración alguna de parte de éste. ¿Cómo negarle a esta mujer una compensación por el sacrificio realizado durante el matrimonio considerando que los beneficios derivados del mismo redundaron directamente en el marido?

Sin embargo, la pregunta pertinente no es esa. Los sentenciadores debieron tener presente que las relaciones patrimoniales durante el matrimonio se rigen por el respectivo régimen patrimonial matrimonial. El ámbito de autonomía de los cónyuges les permite decidir libremente al iniciar su vida matrimonial si han de regirse por un estatuto comunitario o de separación de patrimonios. Tal decisión desplegará sus efectos más visibles generalmente una vez que el matrimonio termine por alguna causa legal. Lo mismo ocurre con la distribución del trabajo dentro del matrimonio: el acuerdo acerca de quién asumirá el trabajo doméstico y quién el remunerado, y en qué medida, corresponde privativamente a los cónyuges, según su proyecto de vida en común. No puede un tribunal, cuando ese proyecto de vida se ha frustrado, asumir la "revisión" de tales acuerdos conyugales so pretexto de hacer justicia entre los cónyuges. En este sentido, la doctrina nacional ha recalcado que la compensación económica es una institución de derecho estricto, es decir, que sólo procede cuando concurren los presupuestos legales señalados en el art. $61 \mathrm{LMC}$, que no se presume sino que requiere de prueba y que no pretende una nivelación ex post de las relaciones patrimoniales derivadas del matrimonio sino el resarcimiento del menoscabo económico sufrido por el cónyuge beneficiario. Ninguno de estos aspectos se tuvo en cuenta en el fallo de segunda instancia. En efecto, en el caso resuelto la mujer solicitante de compensación económica desarrolló una actividad remunerada o lucrativa durante el matrimonio (y probablemente lo hizo en mayor medida de lo que quería o podía, según los términos del mencionado artículo), y por consiguiente, mal podría cumplirse con el presupuesto de que la falta de trabajo remunerado haya sido "consecuencia de haberse dedicado al cuidado de los hijos o a las labores propias del hogar común”. Por otra parte, el menoscabo económico -requisito fundamental de la prestación compensatoria- se da por sentado a partir de la mejor situación económica del marido en comparación con la de la mujer, sin expresarse los criterios cuantificadores del art. 62 inc. $1^{\circ}$ LMC utilizados para su cálculo. En definitiva, pareciera que la Corte de Apelaciones asimiló el menoscabo compensable con el daño más bien de orden extrapatrimonial sufrido por la mujer durante el matrimonio como consecuencia de que su sacrificio en pos del marido no fue equitativamente retribuido por éste. Desde luego que una reparación de este tipo puede ser procedente pero no a 
través de la compensación económica sino que utilizando el régimen general de responsabilidad civil. Sólo la verificación estricta de los presupuestos de la compensación económica puede garantizar que la institución cumpla su finalidad resarcitoria del daño patrimonial que para estos efectos es relevante jurídicamente y no degenere en una medida punitiva frente a los abusos que uno de los cónyuges pueda haber cometido durante la vigencia del matrimonio. 